\title{
Cultivo in vitro de Embriones Inmaduros en tres Citotipos de Brachyopodium distachyon (L.) P. Beauv.
}

\author{
R. Hammami ${ }^{*} 1$, E. Friero ${ }^{* *}$, C. Soler ${ }^{* *}$, N. Jouve ${ }^{* *}$ y J.M. González ${ }^{* *}$ \\ * Departamento de Pomology, EEAD-CSIC Av. Montañana 1005- 50059 Zaragoza (Spain) \\ ** Departamento de Biología Celular y Genética, Campus Universitario, Universidad de Alcalá, 28871 \\ Madrid (España) \\ *** Departamento de Medio Ambiente del I.N.I.A., Finca La Canaleja, Alcalá de Henares (Madrid)
}

\section{Resumen}

En este trabajo se ha analizado la respuesta al cultivo in vitro de muestras de seis poblaciones de Brachypodium distachyon (dos por cada uno de los citotipos $2 n=10 ; 2 n=20 ; 2 n=30$ ), para lo cual se ha partido de embriones cigóticos inmaduros que fueron sembrados en nueve medios de inducción de callos (BR1 a BR9), que se diferenciaban entre sí en el regulador de crecimiento utilizado (Ácido 2,4-Diclorofenoxiacético (2,4-D), Piclorán o Dicamba) y en su concentración (1, 2 ó 4 mg/l). Para cada uno de los medios utilizados se han realizado cuatro repeticiones de 20 embriones por tratamiento. Los resultados obtenidos fueron analizados posteriormente mediante un análisis de la varianza (ANOVA) de las variables: $n^{\circ}$ de callos totales $/ \mathrm{n}^{\circ}$ total de embriones (TC); $\mathrm{n}^{\circ}$ de callos compactos $/ \mathrm{n}^{\circ}$ total de callos (CC); $\mathrm{n}^{\circ}$ de callos blandos $/ \mathrm{n}^{\circ}$ total de callos (SC). La respuesta ha sido muy variable, tanto para el número como para el tipo de callo formado, dependiendo de la población y el medio de cultivo empleado. Así, las muestras con $2 n=30$ cromosomas son las que han dado lugar a un mayor número de callos totales y también de callos embriogénicos. La mejor respuesta se obtuvo en aquellos medios de cultivos que contenían 2,4-D, con independencia de la concentración. Los callos obtenidos se distribuyeron al azar en cuatro grupos y se sembraron en un medio de regeneración (G1) conteniendo BAP $(0,5 \mathrm{mg} / \mathrm{l})$ y se incubaron en una cámara climática con un fotoperiodo de $14 \mathrm{~h}$ de luz y $22^{\circ} \mathrm{C}$ de temperatura constante. Al cabo de un mes se contabilizó el número de brotes formados (verdes o albinos) y se calcularon las siguientes variables: $n^{\circ}$ de brotes totales (verdes+ albinos) $/ \mathrm{n}^{\circ}$ total de callos (TSV), $\mathrm{n}^{\circ}$ de brotes verdes $/ \mathrm{n}^{\circ}$ total callos (TSVC), $\mathrm{n}^{\circ}$ de brotes verdes a partir de callos compactos $/ \mathrm{n}^{\circ}$ total callos compactos (SCC), $\mathrm{n}^{\circ}$ de brotes verdes a partir de callos blandos $/ \mathrm{n}^{\circ}$ total callos blandos (SSC) y $n^{\circ}$ total brotes verdes $/ n^{\circ}$ total embriones (R). Los ANOVA de estas variables, revelaron diferencias significativas entre las poblaciones para cada una de las variables estudiadas.

Los seis genotipos han sido clasificados en función de su aptitud para la regeneración de plantas a partir del cultivo in vitro de embriones inmaduros (variable R). Así, las dos poblaciones con $2 \mathrm{n}=30$ cromosomas, $\mathrm{Bd} 238$ y Bd341, fueron las de mejor comportamiento mientras que las poblaciones $\mathrm{Bd} 160 \mathrm{y}$ 'Zulema' con $2 \mathrm{n}=10$ cromosomas, mostraron la respuesta más baja.

Palabras clave: Brachypodium distachyon, embriones inmaduros, citotipos, cultivo in vitro.

\section{Abstract \\ In vitro culture of inmature embryos in three cytotypes of Brachypodium distachyon (L.) P. Beauv.}

In this work the in vitro culture response of six population samples of Brachypodium distachyon (two by each one of the cytotypes of $2 n=102 n=20 ; 2 n=30$ ) has been analyzed. Immature zygotic embryos

1. Autor para correspondencia: rifkah82@yahoo.fr http://dx.doi.org/10.12706/itea.2013.016 
were seeded for callus induction in nine culture media (BR1 to BR9), that were different to each other in the growth regulator kind of (2, 4-dichlorophenoxyacetic acid (2, 4-D), Picloran or Dicamba) and concentration (1, 2 or $4 \mathrm{mg} / \mathrm{l})$, with four repetitions with 20 embryos per treatment. Results were subsequently analyzed using an ANOVA test for the following variables:TC = total calluses number / total embryos number; $\mathrm{CC}=$ compact calluses number / total calluses number; $\mathrm{SC}=$ soft calluses number/ total calluses number. A very different response among them, as much for the number as for the type of callus developed, has been observed, based on the genotype and culture medium used. Thus, the samples with $2 n=30$ chromosomes gave rise to a greater number of total calluses and embryogenic calluses. The culture mediums that induced the best response were those that contained 2, 4-D in all the concentrations tested. The obtained calluses were distributed in four repetitions and they were seeded in the regeneration media containing N6-benzyl-aminopurine BAP $(0.5 \mathrm{mg} / \mathrm{l})$ and were transferred to a chamber growth with a photoperiod of $14 \mathrm{~h}$ light and a constant temperature of $22^{\circ} \mathrm{C}$. After a month, the number of developed buds (green or albinos) was counted and were estimated the following variables: TSV = total number of buds (green + albinos) $/$ total number of calluses; TSVC = number of green buds / total number of calluses; SCC = number of green buds from compact calluses / total number of compact calluses; SSC = number of green buds from soft calluses /total number of soft calluses; Total green buds/total immature embryos (R). The ANOVA test for each one of the variables revealed significant differences between the populations. The study of the variable $R$, that summarizes the response of the in vitro culture, has allowed classifying the six populations based on its aptitude for the regeneration of plants from the in vitro culture of immature embryos. Thus, two populations of $2 n=30$ chromosomes, $\mathrm{Bd} 238$ and $\mathrm{Bd} 341$ were those of the best behavior, whereas the populations $\mathrm{Bd} 160$ and 'Zulema' with $2 \mathrm{n}=10$ chromosomes, showed the lowest response.

Key words: Brachypodium distachyon, immature embryos, cytotypes, in vitro culture.

\section{Introducción}

Brachypodium distachyon $(2 \mathrm{n}=10)$ se ha propuesto como especie modelo de los cereales de climas templados entre los que se encuentran el trigo, la cebada y el centeno (Draper et al., 2001). Esta especie presenta una serie de ventajas para llevar a cabo estudios de genómica funcional. Entre ellas destacan su pequeño genoma (335-400 $\mathrm{Mpb})$, la reproducción autógama, el pequeño porte, su ciclo vegetativo corto (11 a 18 semanas), la sencillez de cultivo y la posibilidad de su cultivo a altas densidades de siembra (Opanowicz et al., 2011). Actualmente, se incluyen dentro de esta especies otros citotipos con $2 n=20$ y $2 n=30$ cromosomas, aunque estudios recientes indican que el citotipo con $2 n=20$ podría tratarse de una especie diferente y el de $2 n=30$ sería un anfiploide entre las formas de 10 y las de 20 cromosomas (Filiz et al., 2009; Hammami et al., 2011b). Recientemente, Catalán et al. (2012) han propuesto que los tres citotipos se corresponden con tres especies diferentes que serían Brachypdium distachyon $(2 \mathrm{n}=$ $10), B$. stacei $(2 n=20)$ y el alopoliploide entre ambas $B$. hybridum $(2 n=30)$. Además, Brachypodium se está comenzando a utilizar en la protección de suelos en terrenos sometidos a erosión por escorrentía como es el caso de los olivares (Soler et al., 2004). Así, se han comercializado líneas de Brachypodium con $2 \mathrm{n}=10$ ('Zulema') y con $2 \mathrm{n}=30$ ('Ibros').

Además de otras características, es deseable que una especie modelo posea una buena respuesta al cultivo in vitro, ya que muchas de las aplicaciones a desarrollar y de los estudios básicos que se deseen hacer, requieren la posibilidad de regenerar plantas adultas y fértiles a partir de células o tejidos. En este sentido, desde la proposición de $B$. distach- 
yon como modelo de cereales de climas templados, se han llevado a cabo estudios de respuesta al cultivo in vitro en diferentes poblaciones (Bablak et al., 1995; Draper et al., 2001 Hammami et al., 2011a).

En gramíneas, se han desarrollado diferentes medios de cultivo con el fin de inducir la embriogénesis somática a partir de embriones inmaduros, con respuestas muy variables (González et al., 2001; Kilinic, 2004; Sener et al., 2008). De acuerdo con Evans et al. (1981) la mayoría de los sistemas embriogénicos requieren de una concentración alta de auxina en el medio para la inducción de los embriones somáticos. En el caso de las gramíneas, la auxina más utilizada es el ácido 2,4-Diclorofenoxiacético (2,4-D). Otras auxinas sintéticas tales como el Picloran, el ácido 2-benzothiazol acético y el ácido paraclorofenoxiacético también han resultado ser bastante efectivas en algunos casos (Kilinic, 2004; Sener et al., 2008).

Previo a este trabajo se llevó a cabo un estudio de cultivo in vitro de embriones inmaduros de una colección de 23 poblaciones autóctonas españolas de $B$. distachyon y dos líneas comerciales 'Ibros' y 'Zulema' en dos medios de inducción de embriogénesis somática: MS y MSm diferenciados solamente por el tipo de azúcar añadido al medio (Hammami et al., 2011a). Los resultados de este trabajo mostraron una amplia diversidad genética en la respuesta al cultivo in vitro de embriones inmaduros, de manera que la colección abarca poblaciones recalcitrantes al cultivo y otras con respuestas aceptables. En el presente trabajo se estudiaron seis poblaciones de B.distachyon (dos por cada citotipo) y se ensayaron nueve medios de inducción de embriogénesis somática. Los medios se basaron en el puesto a punto previamente (Hammami et al., 2011a) y se diferenciaron en el tipo de auxina (ácido 2.4-Diclorofenoxiacético (2,4-D), Picloran o Dicamba) y en su concentración en el medio de inducción (1 $\mathrm{mg} / \mathrm{l}, 2 \mathrm{mg} / \mathrm{l}$ y $4 \mathrm{mg} / \mathrm{l})$. Con este estudio se pretende estudiar: $i)$ - la respuesta al cultivo in vitro de los 3 citotipos $(2 n=10,20$ y 30$)$ de Brachypodium, ii)- la influencia del regulador de crecimiento y su concentración en la estimulación de la capacidad embriogénica en las tres formas, iii)- la capacidad para regenerar plantas a partir de los callos obtenidos en la fase anterior.

\section{Materiales y métodos}

\section{Material Vegetal}

Se han utilizado embriones inmaduros procedentes de cinco poblaciones silvestres de Brachypodium distachyon, con diferentes números cromosómicos: Bd160 y la variedad comercial 'Zulema' con $2 \mathrm{n}=10$; Bd114 y Bd115 con 2n = 20; Bd 238 y Bd341 con $2 n=$ 30 . Las poblaciones silvestres fueron recolectadas por el grupo que dirige la Dra. Soler en varias expediciones en los últimos años en distintas localidades de la Península ibérica. Este material está incluido dentro de una amplia colección de especies de gramíneas silvestres españolas que se conserva en la Unidad de Mejora Genética Vegetal del INIA (Departamento de Medio Ambiente, finca La Canaleja, Alcalá de Henares). La variedad 'Zulema' fue obtenida por domesticación y selección a partir de una población silvestre por el mismo grupo y ha sido registrada y aprobada por la Oficina de Variedades Europeas para su comercialización por la empresa Agrosa Semillas S.A.

\section{Medios de cultivo}

Se han empleado nueve medios de cultivo. El medio basal consistió en el medio de Murashige y Skoog (1962) suplementado con $30 \mathrm{~g} / \mathrm{l}$ de maltosa y conteniendo 2,4-D, Dicamba o Piclorán a concentraciones de 1, 2 ó 4 mg/l, denominados medios BR1 (1 mg/l 2,4-D) a BR9 (4 mg/l Piclorán). 
Inducción de callos a partir de embriones cigóticos inmaduros de $B$. distachyon

Los embriones se obtuvieron de semillas en formación con una edad entre 15-25 días después de la antesis. Se procedió a la desinfección de las semillas con una solución 1:5 Domestos $^{\mathrm{TM}}$ manteniéndose en esta solución con agitación suave durante 20 minutos. Luego se lavaron 6 veces con agua destilada estéril en una campana de flujo laminar. Las semillas desinfectadas se diseccionaron con pinzas estériles bajo observación con lupa estereoscópica. De cada semilla se extrajo el embrión junto al escutelo colocándose el embrión en contacto con el medio de cultivo. El tamaño de los embriones varió entre 0,3 y 0,7 mm.

Se realizaron cuatro repeticiones de 20 embriones cada una, para cada uno de los medios y población. Las placas se cerraron con Parafilm y se mantuvieron 4 ó 5 semanas en una estufa a $25^{\circ} \mathrm{C}$ y en oscuridad. Se contabilizó el número de callos compactos o embriogénicos, caracterizados por ser de consistencia sólida y con estructuras globulares en su superficie y de callos blandos, caracterizados por su consistencia acuosa. A partir de los datos obtenidos se calcularon las siguientes variables: $n^{\circ}$ de callos totales $/ n^{\circ}$ total de embriones (TC); $n^{\circ}$ de callos embriogénicos $/ \mathrm{n}^{\circ}$ total de callos (CC); $\mathrm{n}^{\circ}$ de callos blandos $/ n^{\circ}$ total de callos (SC). Se ha llevado a cabo un análisis de varianza de dos vías para cada una de las tres variables: TC, CC y SC. Previo a este análisis estadístico, se llevó a cabo la transformación de los valores de las variables con el arc sen $\sqrt{x}$, con el fin de normalizar la distribución. A continuación se realizó un test de LSD (Mínima Diferencia Significativa) con el fin de comparar las medias de cada una de las poblaciones y medios de inducción de callos empleados.
Regeneración de plántulas

Los callos obtenidos se distribuyeron en cuatro repeticiones y se sembraron en un medio de regeneración (G1), similar al medio de inducción de callos pero conteniendo 6-bencilaminopurina $\operatorname{BAP}(0,5 \mathrm{mg} / \mathrm{L})$ como regulador de crecimiento, y se mantuvieron en una cámara climática con un fotoperiodo de $14 \mathrm{~h}$ de luz y $22^{\circ} \mathrm{C}$ de temperatura constante. Al cabo de un mes se contabilizó el número de brotes formados (verdes o albinos) por cada tipo de callo y se calcularon las siguientes variables $\mathrm{n}^{\circ}$ de brotes totales (verdes + albinos) $/ n^{\circ}$ total de callos (TSV), $n^{\circ}$ de brotes verdes $/ \mathrm{n}^{\circ}$ total de callos (TSVC), $\mathrm{n}^{\circ}$ de brotes verdes a partir de callos compactos $/ \mathrm{n}^{\circ}$ total de callos compactos (SCC), $n^{\circ}$ total de brotes verdes a partir de callos blandos $/ \mathrm{n}^{\circ}$ total de callos blandos (SSC), $\mathrm{n}^{\circ}$ total de brotes verdes $/ \mathrm{n}^{\circ}$ total embriones inmaduros (R). Se realizó un análisis de varianza a cada una de las variables estimadas en la fase de regeneración de brotes. Previamente al ANOVA se procedió a la normalización de las variables mediante la aplicación de las siguientes transformaciones, TSC: arc sen $\sqrt{ } \mathrm{x} / 10$, TSVC: $\operatorname{arc} \operatorname{sen} \sqrt{ } \mathrm{x} / 10$, SCC: $\operatorname{arc} \operatorname{sen} \sqrt{ } \mathrm{x} / 100$, SSC: $\operatorname{arc}$ $\operatorname{sen} \sqrt{x} / 10, R: \operatorname{arc} \operatorname{sen} \sqrt{ } x / 10$.

\section{Resultados}

Fase de inducción de callos

El número total de embriones puestos en cultivo en los diferentes medios ha sido de 4.400. Después de un mes de cultivo se observaron diferentes tipos de callos: compactos o embriogénicos, blandos, necróticos y en algunos casos varios tipos diferentes en un mismo callo. 

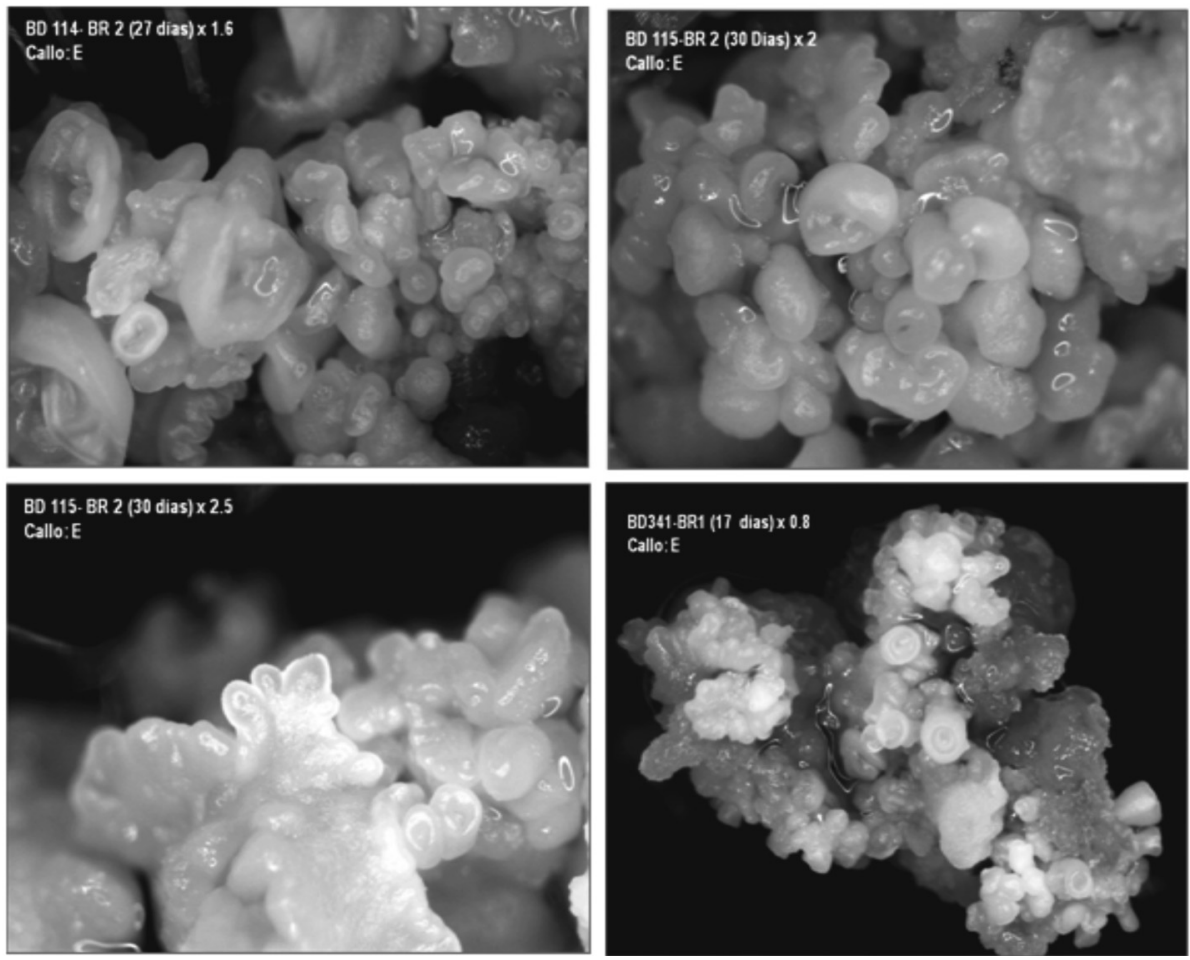

Figura 1. Respuesta a la inducción de callos embriogénicos sobre medios BR1y BR2 de los embriones inmaduros procedentes de Bd114 $(2 n=20), \operatorname{Bd} 115(2 n=20)$ y Bd341 $(2 n=30)$. Ejemplos de callos embriogénicos $(E)$.

Figure 1. Response to embryogenic callus induction on medium $B R 1$ and $B R 2$ of immature embryos from Bd114 $(2 n=20), B d 115(2 n=20)$ and Bd341 $(2 n=30)$. Examples of embryogenic calls $(E)$.
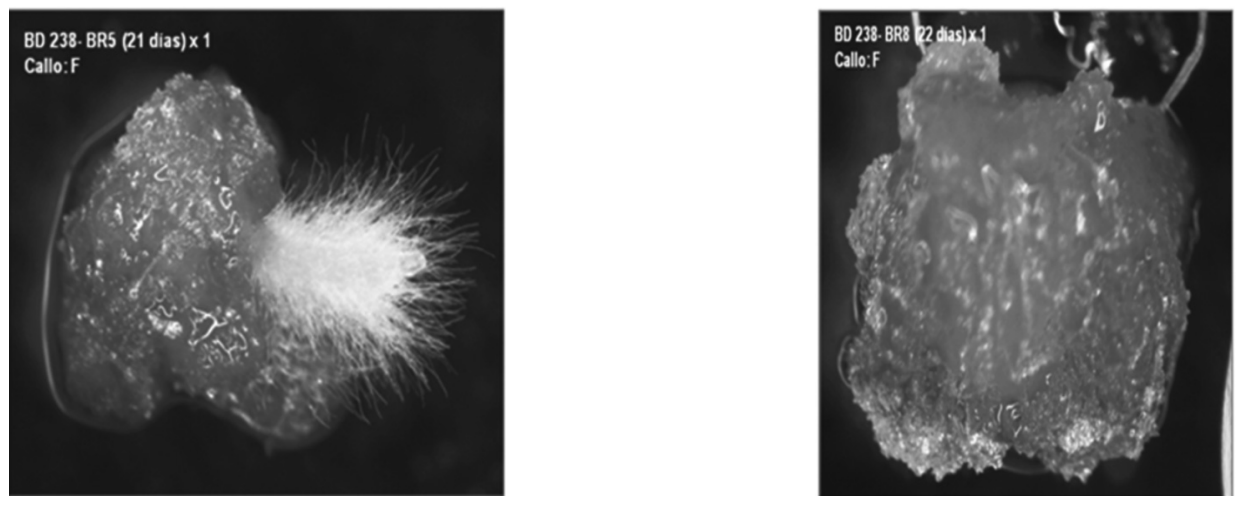

Figura 2. Respuesta a la inducción de callos embriogénicos sobre medios BR3 y BR4 de embriones inmaduros procedentes de Bd114 $(2 n=20)$. Ejemplos de callos fofos $(F)$.

Figure 2. Response to embryogenic callus induction on medium BR3 and BR4 of immature embryos from Bd114 $(2 n=20)$. Examples of soft callus $(F)$. 
En las figuras 1 y 2 se muestran algunos ejemplos de los diferentes tipos de callos encontrados. A partir de la respuesta de los diferentes citotipos en los 9 medios de cultivo ensayados, se calcularon las variables TC, CC y SC y se llevó a cabo un análisis de varianza en función de la población, medio de inducción de callos y la interacción entre ellos (Tabla 1). Se puede observar que en todos los casos las diferencias fueron altamente significativas. El test de LSD ha permitido agrupar los genotipos en función de su respuesta para las diferentes variables. En el caso de la variable TC, las poblaciones con $2 \mathrm{n}=20$ cromosomas (Bd114 y Bd115) son las que dieron los valores más bajos y se comportaron de manera diferente al resto de las poblaciones, que no mostraron diferencias significativas entre ellas (Tabla 2).

Tabla 1. Resultados del ANOVA de las tres variables analizadas:

$\mathrm{n}^{\circ}$ de callos totales $/ \mathrm{n}^{\circ}$ total de embriones (TC); $\mathrm{n}^{\circ}$ de callos compactos $/ \mathrm{n}^{\circ}$ total de callos (CC); $\mathrm{n}^{\circ}$ de callos blandos $/ \mathrm{n}^{\circ}$ total de callos (SC)

Table 1. Results of the ANOVA of three analyzed variables: TC = total calluses number / total embryos number; CC = compact calluses number / total calluses number; $\mathrm{SC}=$ soft calluses numberl total calluses number

\begin{tabular}{|c|c|c|c|c|c|}
\hline Variables & Fuente Variación & g.l & Suma de Cuadrados & Media de Cuadrados & Coeficiente-F \\
\hline \multirow[t]{5}{*}{$\mathrm{TC}$} & Población (G) & 5 & 46802 & 9360 & $35,16 * * *$ \\
\hline & Medio (M) & 8 & 21677 & 2709 & $10,18 * * *$ \\
\hline & $\mathrm{G} \times \mathrm{M}$ & 40 & 19913 & 497 & $1,87 * * *$ \\
\hline & Residuos & 162 & 43129 & 266 & - \\
\hline & Total & 215 & 131523 & - & - \\
\hline \multirow[t]{5}{*}{$\mathrm{CC}$} & Población (G) & 5 & 63824 & 12764 & $47,95 * * *$ \\
\hline & Medio (M) & 8 & 37106 & 4638 & $17,42 * * *$ \\
\hline & $\mathrm{G} \times \mathrm{M}$ & 40 & 48010 & 1200 & $4,51 * * *$ \\
\hline & Residuos & 162 & 43125 & 266 & \\
\hline & Total & 215 & 192067 & & \\
\hline \multirow[t]{5}{*}{ SC } & Población (G) & 5 & 106453 & 21290 & $53,86 * * *$ \\
\hline & Medio (M) & 8 & 16332 & 2041 & $5,16 * * *$ \\
\hline & $\mathrm{G} \times \mathrm{M}$ & 40 & 45325 & 1133 & $2,87 * * *$ \\
\hline & Residuos & 162 & 64037 & 395 & - \\
\hline & Total & 215 & 232147 & & - \\
\hline
\end{tabular}

$* * *$ significativa $\mathrm{p}<0,001$.

Los callos embriogénicos son los que presentan un mayor interés por ser los que generalmente presentan una mayor capacidad para regenerar plántulas. Por ello se ha realizado un estudio de la producción de los callos embriogénicos y también de los callos blandos en las seis poblaciones utilizadas. El análisis de varianza mostró diferencias significativas en todos los casos y el test de LSD realizado para la variable CC indica la existencia de diferencias entre las muestras procedentes de las poblaciones de distintos niveles cromosómicos. 
Bd160 y 'Zulema', con $2 n=10$, son las que presentaron una respuesta más baja mientras que $\mathrm{Bd} 238$ y Bd341 con $2 \mathrm{n}=30$ y Bd115 ( $2 \mathrm{n}$ $=20$ ) presentaron la respuesta más alta. Respecto a la variable SC, las muestras de $2 n=10$ cromosomas son los que dieron valores más altos, estadísticamente diferentes a los restantes y en especial a los que tiene $2 n=20$, que son los que mostraron los valores más bajos (Tabla 2 ).

Tabla 2. Resultados de la comparación múltiple de las distintas poblaciones analizadas para las variables TC, CC, y SC. Poblaciones seguidas de

la misma letra no son significativamente diferentes (Test LSD)

Table 2. LSD Results of different populations for the variables TC, CC and SC

\begin{tabular}{lccc}
\hline & \multicolumn{3}{c}{ Variables } \\
\hline Población & TC & CC & SC \\
\hline Bd160 & b & a & d \\
'Zulema' & b & a & d \\
Bd114 & a & b & a \\
Bd115 & a & c & a \\
Bd238 & b & c & c \\
Bd341 & b & c & b \\
\hline
\end{tabular}

Se realizó un ANOVA de cada una de las variables (TC, CC y SC) en función del medio de inducción de callos (BR1 a BR9) y también se aplicó un test de LSD. Los resultados obtenidos indican que para el caso de las variables TC y CC los medios BR1, BR2 y BR3 que están suplementados con tres concentraciones diferentes del 2.4-D (1 mg/l, $2 \mathrm{mg} / \mathrm{l}$, y $4 \mathrm{mg} / \mathrm{l}$, respectivamente) y el medio BR6 conteniendo Dicamba (4 mg/l) fueron los que en mayor medida favorecieron la formación de callos totales y en particular de callos compactos, mientras que en los medios BR7, BR8 y BR9 preparados con Piclorán (1 mg/l, 2mg/l y $4 \mathrm{mg} / \mathrm{l}$, respectivamente) son los que presentaron los valores más bajos para estas variables (Tabla 3). Respecto a la variable SC, la diferencia entre los nueve medios no es tan clara, aunque en general los medios suplementados con Piclorán indujeron una mayor proporción de callos blandos (Tabla 3).

Tabla 3. Resultados de la comparación múltiple de los distintos medios de cultivo analizados para las variables TC, CC, y SC. Poblaciones seguidas de la misma letra no son significativamente diferentes (Test LSD) Table 3. LSD Results of different culture mediums for the variables TC, CC and SC

\begin{tabular}{|c|c|c|c|}
\hline \multirow[b]{2}{*}{ Medio } & \multicolumn{3}{|c|}{ Variables } \\
\hline & $\mathrm{TC}$ & $\mathrm{CC}$ & SC \\
\hline BR1 & $\mathrm{cd}$ & $d$ & $a b$ \\
\hline BR2 & $d$ & $d$ & $a b$ \\
\hline BR3 & $d$ & $d$ & $a$ \\
\hline BR4 & $a b$ & $\mathrm{a}$ & $a b c$ \\
\hline BR5 & bc & bcd & $a b c$ \\
\hline BR6 & bcd & $\mathrm{cd}$ & $a b c$ \\
\hline BR7 & $a$ & $a$ & $\mathrm{bc}$ \\
\hline BR8 & $a b$ & $a b$ & C \\
\hline BR9 & $a b$ & $a b c$ & c \\
\hline
\end{tabular}

Fase de regeneración de plántulas

La obtención de brotes verdes a partir de los callos, es una de las etapas más críticas en el proceso de cultivo in vitro vegetal. Los callos obtenidos en cada uno de los nueve medios de inducción (BR1 a BR9) se distribuyeron en cuatro réplicas y fueron sembrados en el medio de germinación G1. En la Figura 3 se muestran imágenes de plántulas obtenidas a partir de diferentes poblaciones. 
Tabla 4. Resultado del ANOVA de las variables analizadas: $n^{\circ}$ de brotes totales (verdes+ albinos) $/ n^{\circ}$ total de callos (TSV), $n^{\circ}$ de brotes verdes $/ n^{\circ}$ total callos (TSVC), $n^{\circ}$ de brotes verdes a partir de callos compactos $/ \mathrm{n}^{\circ}$ total callos compactos (SCC), $\mathrm{n}^{\circ}$ de brotes verdes a partir de callos blandos $/ \mathrm{n}^{\circ}$ total callos blandos (SSC) y $n^{\circ}$ total brotes verdes $/ n^{\circ}$ total embriones (R)

Table 4. Result of the ANOVA of analyzed variables : TSV = total number of buds (green + albinos) / total number of calluses; TSVC = number of green buds / total number of calluses; SCC = number of green buds from compact calluses / total number of compact calluses; SSC = number of green buds

from soft calluses /total number of soft calluses; Total green buds/total immature embryos $R$

\begin{tabular}{llrccc}
\hline Variables & Fuente Variación & g.l & Suma de Cuadrados & Media de Cuadrados & Coeficiente-F \\
\hline TSC & Entre poblaciones & 5 & 2084 & 416 & $17,61 * * *$ \\
& Dentro población & 18 & 425 & 23 & - \\
& Total & 23 & 2510 & - & - \\
\hline TSVC & Entre poblaciones & 5 & 1787 & 357 & $17,29 * * *$ \\
& Dentro población & 18 & 372 & 10 & - \\
& Total & 23 & 2159 & - & $16,57^{* * *}$ \\
& Entre poblaciones & 5 & 853 & 170 & - \\
\hline SCC & Dentro población & 18 & 185 & 10 & - \\
& Total & 23 & 1039 & - & 3,87 (ns) \\
& Entre poblaciones & 5 & 689 & 137 & - \\
\hline SSC & Dentro población & 18 & 641 & 35 & $17,07 * * *$ \\
& Total & 23 & 1331 & - & - \\
\hline R & Entre poblaciones & 5 & 1701 & 340 & - \\
& Dentro población & 18 & 358 & 19 & - \\
& Total & 23 & 2060,71 & & - \\
& & &
\end{tabular}

$* * *=$ significativa $\mathrm{p}<0,001 ;$ (ns) $=$ no significativa.

A partir de los resultados obtenidos se calcularon las variables TSVC, TSC, SCC, SSC y $R$ y se llevó a cabo un ANOVA. En la Tabla 4, se muestran los resultados del análisis de la varianza de las cinco variables estudiadas. En todos los casos se han observado diferencias estadísticamente significativas, excepto para la variable SSC. La falta de significación para los brotes verdes derivados de callos blandos, probablemente se debe al pequeño número de callos blandos que regeneraron plantas, con una notable variación entre las distintas poblaciones y con desviaciones típicas muy grandes, que hacen que las comparaciones resulten no significativas.

Se ha aplicado un test de LSD para las cuatro plántulas restantes con el fin de agrupar las poblaciones que presentan una respuesta similar. Los resultados se detallan en la Tabla 5.

En general se observa que, para las variables TSC, TSVC, SCC y $R$ las poblaciones con $2 n$ $=30, \mathrm{Bd} 238$ y $\mathrm{Bd} 341$ son las que muestran mayores valores, mientras que las poblaciones con $2 \mathrm{n}=10$, Bd160 y 'Zulema' son las que presentan valores más bajos. 

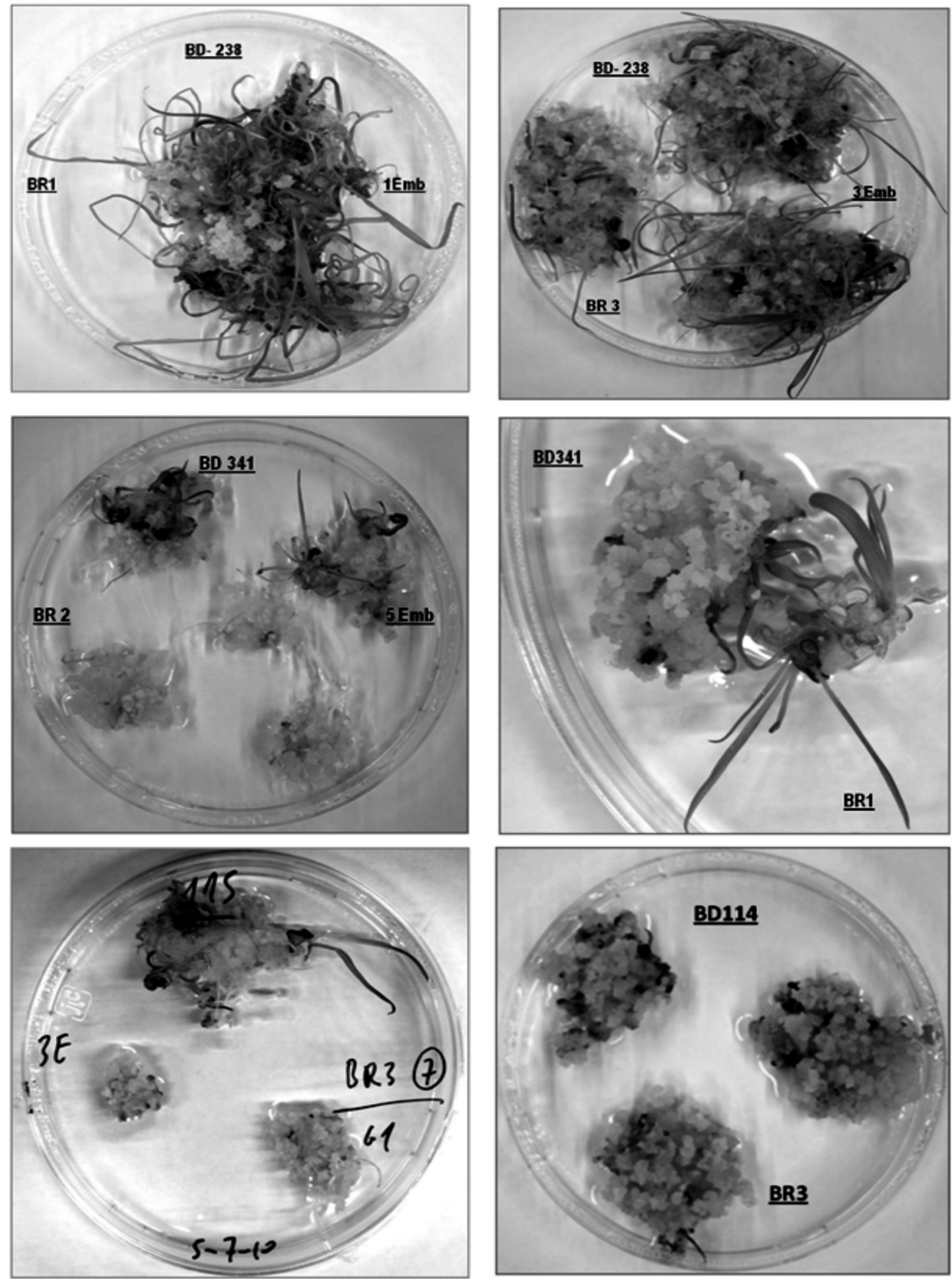

Figura 3. Resultados de la regeneración de brotes verdes a partir de callos compactos de las poblaciones Bd238, Bd341, Bd115 y Bd114, obtenidos en los medios de inducción BR1, BR2 y BR3.

Figure 3. Results of green shoot regeneration of compact callus from BD238 Bd341, and Bd114 Bd115 obtained in induction medium BR1, BR2 and BR3. 
Tabla 5. Resultados de la comparación múltiple de las distintas poblaciones analizadas para las variables TSV, TSVC, SCC, y R. Poblaciones seguidas de la misma letra no son significativamente diferentes (Test LSD)

Table 5. LSD Results for the variables TSV, TSVC, SCC, SSC and R

\begin{tabular}{lccccc}
\hline Población & \multicolumn{5}{c}{ Variables } \\
\hline Bd160 & TSC & TSVC & SCC & SSC & R \\
'Zulema' & a & a & a & a & a \\
Bd114 & a & ab & b & ab & ab \\
Bd115 & b & bc & ab & a & abc \\
Bd238 & b & $c$ & $b$ & $a$ & $b c$ \\
Bd341 & c & d & $c$ & ab & d \\
\hline
\end{tabular}

La variable $\mathrm{R}$ puede considerarse como una estimación global de la capacidad de una población dada para regenerar brotes a partir del cultivo in vitro de embriones inmaduros. La población Bd238 es la que mostró un valor más elevado, al alcanzar las 2,21 plantas regeneradas por embrión inmaduro cultivado in vitro. Este valor es casi cinco veces superior al de la población Bd341 que alcanzó un valor de 0,47.

\section{Discusión}

En los últimos años se ha propuesto a Brachypodium distachyon como especie modelo de los cereales de climas templados, por lo que es necesario contar con herramientas que permitan abordar tanto estudios básicos como aplicaciones biotecnológicas. Así, es necesario disponer de protocolos de cultivo in vitro, que permitan regenerar plantas a partir de diferentes explantes y además disponer de genotipos que respondan adecuadamente al cultivo in vitro. En este trabajo se ha estudiado la respuesta al cultivo in vitro de embriones inmaduros de una muestra de pobla- ciones silvestres de la especie $B$. distachyon con diferente número de cromosomas, recolectadas en la Península Ibérica (Soler et al., 2004). Además, en la vertiente aplicada interesa como fuente de obtención de variedades útiles para la protección de suelos, especialmente en relación con cultivos leñosos.

En cereales, los embriones inmaduros son los explantes que mejor respuesta han mostrado al cultivo in vitro. (Ahloowalia, 1982; González et al., 2001; Rikiishi et al., 2003; Halámkova et al., 2004; Li et al., 2006; Chauhan et al., 2007). En el caso de B. distachyon se han obtenido callos embriogénicos y regeneración de plantas con anterioridad al presente trabajo, si bien en un reducido número de materiales (Bablak et al., 1995; Christiansen et al., 2005; Bahar et al., 2008), no habiéndose llevado a cabo una comparación de resultados entre citotipos con diferente número de cromosomas.

A la vista de los resultados obtenidos en un ensayo previo de cultivo in vitro limitado a dos medios de cultivo (Hammami et al., 2011a), se eligieron seis poblaciones con diferentes números cromosómicos. A partir de estos materiales se ha llevado a cabo un es- 
tudio sobre la influencia de los diferentes niveles cromosómicos de las poblaciones analizadas, el tipo y la concentración de la auxina añadida a los medios (2,4-D, Dicamba o Piclorán) y la interacción 'medio x población'.

En la primera etapa del cultivo, consistente en la inducción de callos, se analizaron tres variables diferentes: TC, CC y SC, y se aplicó un ANOVA y un test de LSD para cada una de ellas. Todos los ANOVA resultaron significativos tanto para el genotipo, el medio de cultivo y su interacción. Del análisis global de los resultados de esta primera fase hay que señalar que las poblaciones con $2 n=10$ fueron las que produjeron callos compactos en menor cantidad y mayor de callos blandos. Las poblaciones con $2 n=20$ y $2 n=30$ tuvieron un comportamiento similar para la producción total de callos y diferente de las poblaciones de 10 cromosomas. Respecto a la producción de callos compactos fueron las poblaciones con $2 \mathrm{n}=30$ y la población Bd 115 $(2 n=20)$ las que tuvieron una respuesta similar y más alta. El análisis de varianza de la variable CC mostró diferencias estadísticamente significativas entre los distintos materiales ensayados para las tres variables citadas. Además, el test de LSD aplicado a los datos reveló también la existencia de diferencias significativas entre las muestras pertenecientes a las poblaciones de distintos niveles cromosómicos. Los materiales de menor número de cromosomas $(2 n=10)$ son los que manifestaron las respuestas más bajas en cuanto a la producción de callos compactos/total de callos formados. Son además los que produjeron un porcentaje más alto de callos blandos. Los restantes materiales, con $2 n=20$ y $2 n=30$, presentaron unas buenas respuestas con niveles más altos para esta variable.

La influencia de la composición del medio en el desarrollo de los embriones inmaduros ha sido estudiada en trabajos previos de otros autores (Carman et al., 1988; Hanzel et al., 1985). En este sentido, Elwafa y Ismail (1999), y Alok et al. (1999), han propuesto que la formación de callos depende de varios factores determinantes tales como el tipo del explante (Vasil, 1994) y su estado de maduración (Varshney et al., 1996), el tamaño del embrión (Draper et al., 2001) y la composición nutricional del medio de cultivo empleado (Mathias y Simpson, 1986; Ahmad et al., 2002).

Los resultados del presente trabajo confirman lo observado por Serhantová et al. (2004), que analizaron la respuesta al cultivo in vitro de 13 cultivares de cebada en medios suplementados con 2,4-D, Dicamba y Piclorán. De los 13 genotipos, en 11 de ellos se obtuvieron los porcentajes más altos de callos embriogénicos en los medios que contenían 2,4-D. De estos 11 genotipos en 8 de ellos no se encontraron diferencias significativas entre los medios que contenían Dicamba o Piclorán y concluyeron que la mejor respuesta la presentan los embriones sembrados en medios preparados con 2,4-D a una concentración igual a 2,5 mg/l. De igual manera, Sikandar et al. (2007), estudiaron la respuesta al cultivo de embriones maduros en dos variedades de trigo harinero y sugirieron que la frecuencia de callos embriogénicos variaba en función de la concentración de 2,4-D y observaron un potencial máximo a una concentración de $3,5 \mathrm{mg} / \mathrm{l}$ en las variedades utilizadas. También, Shafquat et al. (2009) estudiaron la respuesta al cultivo in vitro de tres variedades de Triticum aestivum en diferentes concentraciones de auxinas y sugirieron que la variedad 'Khirman' produjo un porcentaje alto de callos compactos en un medio suplementado con 2.4-D (1 mg/l) + kin (1 mg/l) + NAA (2 $\mathrm{mg} / \mathrm{l})$ mientras que la variedad 'Soghat-90' mostró la misma repuesta en los diferentes medios de cultivo. Kilinc (2004) analizó el comportamiento al cultivo in vitro de embriones maduros procedentes de siete cultivares de trigo blando en medios preparados con distintas concentraciones de Dicamba $(2,5 ; 5 ; 7,5$ y $10 \mathrm{mg} / \mathrm{l})$ y sus resultados mostra- 
ron que la tasa de formación de callos está influida significativamente por el genotipo y la concentración de auxina, obteniéndose las tasas más altas de callos cuando se empleó una concentración de $5 \mathrm{mg} / \mathrm{l}$ de Dicamba.

En nuestro estudio, los medios BR1, BR2 y BR3 que contienen la auxina 2,4-D a unas concentraciones de $1 \mathrm{mg} / \mathrm{l}, 2 \mathrm{mg} / \mathrm{l}$ y $4 \mathrm{mg} / \mathrm{l}$, respectivamente, son los que mejor respuesta ofrecieron a la producción de callos embriogénicos. Por el contrario, los medios BR7, BR8 y BR9, que contienen Piclorán (1 mg/l, 2 $\mathrm{mg} / \mathrm{l}$ y $4 \mathrm{mg} / \mathrm{l}$, respectivamente) ofrecieron los valores más bajos de formación de callos embriogénicos y unos porcentajes altos de callos blandos.

Las poblaciones con números de cromosomas superiores ofrecen mejor respuesta, lo que coincide con los resultados obtenidos por Christiansen (2005), que analizó la respuesta al cultivo in vitro a partir de embriones inmaduros de 4 poblaciones de $B$. distachyon y concluyó que los genotipos BDR017 y BDR030 ambos con $2 \mathrm{n}=20$ daban tasas de inducción de callos embriogénicos muy altas y próximas al $91 \%$. Por el contrario, los genotipos BDR001 y BDR018, que poseen un número cromosómico de $2 \mathrm{n}=10$, mostraban unas tasas de inducción de callos más bajas (30\%).

La segunda fase del cultivo in vitro consiste en la regeneración de brotes verdes y constituye una de las etapas más críticas. En el presente estudio esta fase se ha analizado a partir de las variables: TSV, TSVC, SCC, SSC y R. Los análisis estadísticos realizados, ANOVA y test de LSD han resultado significativos en casi todos los casos. Las poblaciones Bd238 y Bd341 (2n = 30) fueron las que ofrecieron la mejor respuesta en cuanto a la regeneración de plántulas. Es de destacar que las poblaciones con $2 n=20$ cromosomas han formado un número de plántulas verdes más bajo del que sería previsible en función de la alta tasa de callos embriogénicos formados en la fase anterior. De hecho, los genotipos de $2 \mathrm{n}=$ 20 , dieron lugar a callos compactos de gran tamaño, cuyas superficies presentaban, en algunos casos, centenares de embriones somáticos. Sin embargo, al pasarlos al medio de germinación, se observó que un gran porcentaje de estos callos apenas producían brotes y tras dos semanas de cultivo aparecían unas zonas necróticas en los callos, que finalmente no dieron lugar a brotes verdes. Este fenómeno no había sido observado en el ensayo preliminar (Hammami et al., 2011a), lo que sugiere una influencia de las condiciones en que se han desarrollado las plantas donadoras de los embriones.

Estos resultados apoyarían los resultados de Hess y Carman (1998), quienes afirmaron que las condiciones ambientales en las que crecen las plantas podrían afectar la concentración endógena de hormonas, ralentizando la capacidad para formar callos embriogénicos, independientemente del genotipo utilizado. De igual manera, Dejan et al. (2010), analizaron la respuesta al cultivo in vitro de 96 genotipos de trigo harinero, demostraron la importancia de los factores climáticos tales como la temperatura y la lluvia en la producción de callos, en el ciclo vegetativo de las plantas.

Papenfus y Carman (1987), Ozgen et al. (1998), y Benkirane et al. (2000), informaron que cuando el trigo se cultiva en condiciones óptimas, la fase de inducción de callos y la fase de regeneración de plantas verdes son fenómenos independientes. Las poblaciones de Brachypodium analizadas en el presente trabajo confirman esta hipótesis y permiten concluir que el proceso de cultivo in vitro está determinado por dos fases separadas en el tiempo y que cada una debe contar con un sistema de control genético distinto (Hammami et al., 2011a). En las fases de crecimiento de embriones o de callos podrían intervenir varios genes reguladores, como han explicado Bhaskaran y Smith (1990) y Bregitzer y Campbell (2001), quienes han sugerido 
además que la fase de regeneración de plántulas podría depender de un sistema poligénico bajo el control de una serie de genes reguladores desconocidos.

Finalmente, la estimación global de la capacidad de una población para regenerar plantas, partiendo del cultivo in vitro de embriones inmaduros y estimada a partir de la variable $R$, indica notables diferencias estadísticamente significativas entre las seis poblaciones evaluadas. Así, Bd238 $(2 \mathrm{n}=30)$ mostró el valor más elevado, alcanzando un porcentaje de 2,21 plantas regeneradas/embrión cultivado, seguida por la población Bd341 $(2 n=30)$ con un valor próximo a 0,47. Las poblaciones que peor aptitud mostraron fueron las de 10 cromosomas y Bd114 ( $2 n=$ $20)$. Estos resultados sugieren que las poblaciones con $2 \mathrm{n}=30$ que actualmente se corresponderían con la especie $B$. hybridum (Catalán et al. 2012) serían los más apropiadas para la regeneración in vitro, y por tanto su aplicación en proyectos biotecnológicos.

\section{Agradecimientos}

Este trabajo ha sido realizado gracias a la financiación del Ministerio de Ciencia e Innovación (proyectos AGL2006-09018-C02-01GL; AGL-2009-10373), R. Hammami, agradece al Ministerio de Educación y Ciencia la beca concedida para la realización de este trabajo (BES-2007-14361).

\section{Bibliografía}

Ahloowalia BS, 1982. Plant regeneration from caIlus culture in wheat. Crop.Sci. 22: 405-410.

Ahmad A, Zhong H, Wang W, Sticklen MB, 2002. Shoot apical meristem. In vitro regeneration and morphogenesis in wheat (Triticum aestivum). In vitro Cell Development. Biol. Plant. 38: 163-167.
Alok V, Jain S, Kathari SL, Varshney A, Jsin S, 1999. Plant regeneration from mature embryos of 20 cultivars of wheat (Triticum aestivum L. and T. durum Desf.). Cereal Res. Comm. 27 (1-2): 163-170.

Bablak P, Draper J, Davey MD, Lynch PT, 1995. Plant regeneration and micropropagation of Brachypodium distachyon. Plant cell Tissue and Organ Culture. 42: 97-107.

Bahar SO, Hernandez P, Filiz E, Budak H, 2008. Brachypodium genomics. Journal of Plant Genomics., doi. 10.1155/2008/536014.

Benkirane H, Abounji Chlyah SA, Chlyah H, 2000. Somatic embryogenesis and plant regeneration from fragments of immature inflorescences and coleoptiles of durum wheat plant. Cell Tissue and Organ Culture 61: 107-113.

Bhaskaran S, Smith RH, 1990. Regeneration in cereal tissue culture. A review. Crop Sci. 30: 13281336.

Bregitzer P, Campbell RD, 2001. Genetic markers associated with green and albino plant regeneration from embryogenic barley callus. Crop. Sci. 41: 173-179.

Carman JG, Jeferson NE, Campbell WF, 1988. Induction of embryogenic Triticum aestivum L. caIli. Quantification of genotype and culture medium effects. Plant Cell Tissue and Organ Culture 12:83-95.

Catalán P, Müller J, Hasterok R, Jenkins G, Mur LA, Langdon T, Betekhtin A, Siwinska D, Pimentel M, López-Alvarez D, 2012. Evolution and taxonomic split of the model grass Brachypodium distachyon. Ann Bot. 109(2) 385-405.

Chauhan H, Srinivas AD, Khurana P, 2007. Comparative analysis of the differential regeneration response of various genotypes of Triticum aestivum, Triticum durum and Triticum dicoccum. Plant Cell Tissue Organ Culture 91: 191-199.

Christiansen $\mathrm{P}$, Andersen CH, Didion T, Folling M, Nielson KK, 2005. A rapid and efficient transformation protocol for the grass Brachypodium distachyon. Plant Cell 23: 751-758.

Dejan DI, Miroslav Z, Mitic N, Radomirka N, Stephen RK, Blazo L, Gordana SM, 2010. Morphologic responses of embryo culture of wheat re- 
lated to environment culture conditions of the explant donor plant. Sci. Agric (Piracicaba. Braz.) $67, n^{\circ} 3$.

Draper J, Mur LAJ, Jenkins G, Ghosh-Biswas GC, Bablak P, Hasterok R, Routledge APM, 2001. Brachypodium distachyon. A New model system for functional genomics in grasses. Plant Physiology 127: 1539-1555.

Elwafa AAA, Ismail AESA, 1999. Callus induction and plant regeneration from cultures of immature embryos of spring wheat. Aust. J. Agric Sci., 303, 13-23.

Evans DA, Sharp WR, Flick CE, 1981. Growth and behavior of cell cultures: Embryogenesis and organogenesis. Thorpe T.A (ed). Tissue culture. Methods and applications in agriculture. Academic Press, Nueva York. Pp: 45-113.

Filiz E, Ozdemir BS, Tuna M, Budak H, 2009. Diploid Brachypodium distachyon of Turkey: Molecular and Morphologic Analysis. T.Yamada and G.Spangenberg (eds.), Molecular Breeding of Forage and Turf, doi: 10.1007/978-0-387-391449_7; @ Spring Science + Busniess Media, LIC 2009.

González JM, Ferrer E, Jouve N, 2001. Influence of genotype and culture medium on callus formation and plant regeneration from immature embryos of Triticum turgidum Desf. Cultivars. Plant breeding vol 120 (6): 513-517.

Halámková E, Vafera J, Ohnoutková L, 2004. Regeneration capacity of calli derived from immature embryos in spring barley cultivars. Biologia Plantarum 48(2): 313- 316.

Hammami R, Cuadrado A, Friero E, Jouve N, Soler C, González JM, 2011a. Callus induction and plant regeneration from immature embryos of Brachypodium distachyon with different chromosome number. Biologia plantarum. 55 (4): 797-800.

Hammami R, Jouve N, Cuadrado A, Soler C, González JM, 2011b. Prolamin storage proteins and alloploidy in wild populations of the small grass Brachypodium distachyon (L.) P. Beauv. Plant Systematic and Evolution. 297, Issue 1-2: 99-111.

Hanzel JJ, Miller JP, Rinkman MAB, Fendos E, 1985. Genotype and media effects on callus formation and regeneration in barley. Crop Sci. 25: 27-31.
Hess JR, Carman JG, 1998. Embryogenic competence of immature wheat embryos: genotype, donor plant environment, and endogenous hormone levels. Crop Sci. 38: 249-253.

Kilinc M, 2004. Effects of dicamba concentration on the embryo cultures of some bread wheat (Triticum aestivum). Genotypes. Biotechnol. And Biotechnol. 58-61 Eq. 18/2004/2.

Li GY, Huang CY, Sui XX, He ZH, Sun QX, Xia XC, 2006. Tissue culture efficiency of different explants from wheat. Journal of Triticeae Crop., 26, 21-25 Mathias R.J., Simpson E.S., 1986. The interaction of genotype and culture medium on tissue culture response of wheat (Triticum aestivum L. em. Thell) callus. Plant Cell Tissue Organ Culture 7: 31-37.

Murashige T, Skoog F, 1962. A revised medium for rapid growth bioassays with tobaco tissue culture. Physiologia Plantarum. 15(3): 473-497.

Opanowicz M, Hands PH, Betts D, Parker ML, Toole GA, Mills ENC, Doonan JH, Drea S, 2011. Endosperm development en Brachypodium distachyon. Journal of Experimental Botany 62(2): 735-748.

Ozgen M, Turet M, Altinok S, Sancak C, 1998. Efficient callus induction and plant regeneration from mature embryo culture of winter wheat (Triticum aestivum L.) genotypes. Plant Cell Reports 18: 331-335.

Papenfus JM, Carman JG, 1987. Enhanced regeneration from wheat callus culture using dicamba and Kinetin. Crop Science 27: 588-593.

Rikiishi K, Matsuura T, Maekawa M, Noda K, Takeda K, 2003. Barley lines allowing prominent high green shoot regeneration in cultures derived from immature embryos. Plant Breeding 122: $105-111$

S, ner O, Can A, Arslan M, Celiktas N, 2008. Effects of genotype and picloram concentrations on callus induction and plant regeneration from immature inflorescence of spring Barley cultivars (Hordeum Vulgare L.). Biotechnol. 22: 915-920.

Serhantová V, Ehrenbergerova J, Ohnoutková L, 2004. Callus induction and plant regeneration efficiency of spring barley cultivars registered in 
the Czech Republic. Plant Soil Environment. 50 (10): 456-462.

Shafquat Y, Imtiaz AK, Abullah K, Nighat S, Ghulam SN, Mohammad AA, 2009. In vitro plant regeneration in bread wheat (Triticum aestivum). Pak. J. Bot. 41 (6): 1869-2876.

Sikandar WA, Israr K, Iqbal M, 2007. Optimization of in vitro conditions for callus induction, proliferation and regeneration in wheat (Triticum aestivum L.) Biotechnology 6(3): 420-425.

Soler C, Casanova C, Rojo A, 2004. Desarrollo de cubiertas vegetales a partir de gramíneas seleccionadas, para su explotación en tierras de olivar. Actas de Horticultura, $n^{\circ} 41$, II Congreso de Mejora Genética de Plantas, León 2004.

Varshney AT, Kant VK, Sharma A, Kothari SL, 1996. High frequency plant regeneration from immature embryo cultures of Triticum aestivum and Triticum. Durum. J. Cereal Res. Commun. 24: 409-416.

Vasil IK, 1994. Molecular improvement of cereals. Plant. Mol. Biol. 25: 925-937.

(Aceptado para publicación el 3 de abril de 2013) 